\title{
QUALITATIVE EVALUATION OF TECHNICAL PARAMETER OF RESILIENCY: A CASE STUDY OF NUWAKOT DISTRICT, NEPAL
}

\author{
Manoj Adhikari ${ }^{*}$, Anupam Raj Bhattarai ${ }^{2}$, Ravi Thapa ${ }^{2}$ \\ ${ }^{1}$ Institute of Engineering, Thapathali Campus, Tribhuvan University, Nepal \\ ${ }^{2}$ Institute of Engineering, Pulchowk Campus, Tribhuvan University, Nepal \\ *Corresponding author: manozadhikari28@gmail.com \\ (Received: September 19, 2020; Revised: November 11, 2020; Accepted: November 21, 2020)
}

\begin{abstract}
The reconstruction work following the 2015 Gorkha Earthquake is being done under the leadership of the National Reconstruction Authority (NRA) by various organizations in coordination with donor agencies and the local people. A detailed study regarding the reconstruction work is necessary to analyze the work done measured in terms of technical, socioeconomic, and sustainability parameters so that the lessons learned from the study could be used in future policymaking and implementation process that aids in achieving an earthquake-resilient community. The study aimed to evaluate the technical parameter of the reconstruction work done in the Nuwakot district until May 2020, according to the Nepal National Building Codes and the latest NRA guidelines. The study was based on qualitative data collected through a Google form survey. The respondents included experts who were working or had worked in different capacities at various organizations involved in reconstruction efforts at the Nuwakot district. The survey covered aspects such as the status of site topography and geology, technical supervision, design and construction, training and capacity building, and use of vulnerable buildings. The study revealed that most of the buildings are compliant with the specified codes/guidelines and are structurally safe. There is a need to improve on the other aforementioned aspects of technical parameters to aid in achieving resiliency.
\end{abstract}

Keywords: Earthquake, Nuwakot, Reconstruction, Resilience, Technical parameter

\section{INTRODUCTION}

Nepal is a country with varied topography. Within less than 200 kilometers, there is a variation of altitude from 59 meters to 8,848 meters (Ministry of Home Affairs, GoN, 2019). Because of its diverse topography and geological position, Nepal has been facing various disasters throughout its history. Landslide, floods, Glacial Lake Outburst Floods (GLOFs), earthquake, fire, drought, and avalanches are some of the frequently occurring natural disasters in Nepal (NDRRP, 2020).

Millions of years ago, the Indian tectonic plate and the Eurasian tectonic plate started to collide with each other. The subduction of the Indian plate into the Eurasian plate gave rise to the Himalayas, and these plate tectonics are still active and gradually thrusting the Himalayas upward. Of the total 2,400 kilometers of the Himalayas, about onethird situated in Nepal makes it highly susceptible to seismic activities (Ministry of Home Affairs, GoN, 2019). The 2015 Gorkha earthquake in Nepal was a result of such active plate tectonics. The devastating earthquake killed over 8000 people, injured more than 21,000, and displaced a further 2 million (Hall et al., 2017). Residential and government buildings, heritage sites, schools and health posts, roads and bridges, water supply systems, agricultural land, trekking routes, hydropower plants, and sports facilities sustained heavy damages (National Planning Commission, GoN, 2015). Nearly 500,000 houses were fully damaged and more than
250,000 houses were partially damaged exposing the lack of seismic-resistant features in these buildings (National Planning Commission, GoN, 2015). After the earthquake, the National Reconstruction Authority (NRA, 2016) was established on 25 December 2015 to lead the reconstruction of the physical damages caused by the earthquake. The reconstruction vision was the establishment of well-planned, resilient settlements, and a prosperous society (NRA, 2016).

\section{Resilient Reconstruction}

The concept of resilience was used to denote the strength and flexibility in various disciplines such as material science and engineering, psychology, sociology, and economics research (Bruneau et al., 2003). As defined by (JRC-EC, 2014), resilience is the quality/ability of systems or communities to recover (or bounce back, or counterbalance, or adjust) following a disruptive event Resilience is not limited to a single structure, but it encompasses technical, social, economic, and environmental issues. Focusing on earthquake preparedness and the response, the term seismic resilience means the ability of both physical and social systems to withstand earthquake forces and to cope with earthquake impacts (Bruneau et al., 2003). Similarly, (Dhungel et al., 2019) have pointed out that reconstruction is not only a technical process but also a social/communal issue. The seismic resilience of a community can be best described by evaluating the following interlinked parameters. 


\section{Technical parameter}

The technical parameter determines whether the physical systems or infrastructures were adequately designed to withstand the earthquake force. Fulfillment of technical criteria ascertains the safety of infrastructures which can be measured by various aspects: site topography and geology, technical supervision, compromised design and construction, training and capacity building, and uses of buildings vulnerable to earthquakes, which is discussed in detail in the following sections.

\section{Sustainability parameter}

Measurement of sustainability parameter decides whether the techniques and materials used have been done sustainably. It governs by the use of local materials and technology, site-specific needs, waste production and management, and environmental impacts of reconstruction.

\section{Socio-economic parameter}

Another fundamental parameter of resilience is socioeconomic. It is evaluated under different aspects: practicability-whether the design serves communityspecific needs, values and the design is acceptable at the community level, ownership-whether the inputs are taken from the community in the designing and policy-making phase, gender equality and social inclusion, economic status-whether people can bear the investment, operation and maintenance cost, and prioritization of marginalized groups.

Several studies have been conducted regarding the reconstruction efforts and the challenges faced after the massive earthquakes. Sharma et al. (2018) have identified inaccessibility, absence of local government, weak governance, weak infrastructures, lack of preparedness, knowledge gap, and manpower shortage as some of the key challenges of the reconstruction to achieve earthquake-resilient community after the 2015 Gorkha earthquake. Whereas, the reconstruction process after the Bam earthquake focused on the involvement of the public so that the reconstruction of houses for survivors would be less dependent on aid provided by the government but the implementation was confined within the manifesto (Fallahi, 2007). The key factor which can be used to measure the effectiveness of the reconstruction process is by analyzing if the lesson learned from the previous experience has helped in introducing improved and timespecific building codes and programs or not (Yaoxian, 1996). Another aspect of effective reconstruction is through better supervision mechanisms which can be gained through decentralization of rights to the community and also denying the one-right housing reconstruction plan (Li et al., 2019).
The reconstruction of private houses in the Nuwakot district is moving forward at a rapid pace. Of the total 77,462 number of beneficiaries; 63,916 houses have already been reconstructed as of May 16, 2020 (NRA, 2020). Buildings have been approved and funds/tranches have been disbursed by the NRA to the homeowners based on the buildings being structurally compliant to the specified codes/guidelines; that process alone does not ensure the establishment of resilient settlements. Other parameters such as technical, socioeconomic, and sustainability should be analyzed in detail to achieve resiliency.

This paper has tried to analyze whether private housing reconstruction in the Nuwakot district has fulfilled the desired level of technical safety according to the Nepal National Building Codes and the latest NRA guidelines, one of the parameter that aids in resiliency, based on the judgments of key experts who are working or have worked in the frontline in the respective areas of the district. Numerous NGOs, INGOs, donor agencies, and government bodies have been involved in reconstruction efforts in the district, which makes it ideal for data collection. The NRA has adopted the owner-driven approach for the reconstruction of private houses as a guiding principle, which means that individual house owners are responsible for and will manage their reconstruction, make their own choices, and mobilize their resources (NRA, 2016). The experts who took part in this survey, have directly contributed to quality control and technical supervision of these private residential houses and training and capacity building in their respective working areas of the Nuwakot district.

\section{MATERIALS AND METHODS}

The primary focus of this paper was on the qualitative evaluation of the technical parameter (topography, supervision, design, capacity building, use of information technology, and structural vulnerability) to evaluate the resiliency of private housing reconstruction in the Nuwakot district, one of the districts severely affected by the 2015 Gorkha Earthquake. The questionnaire for qualitative evaluation was formed based on the similar research works, existing literature on reconstruction as well as the documents published by the Nepal government in reconstruction efforts after the 2015 Gorkha Earthquake. A list of key experts, who had worked or have been working in the different areas of the Nuwakot district through government bodies, donor agencies, and NGOs/INGOs for private housing reconstruction were identified and approached for questionnaire survey. The experts included were civil engineers, civil sub-engineers, assistant civil sub-engineers, social mobilizers, information and documentation officer, and administrative management assistants. 
They were chosen based on their work experience and the geographical distribution of their working areas to obtain representative data of the reconstruction work in Nuwakot. Working areas of the experts include: Bidur Municipality, Likhu Rural Municipality, Kakani Rural Municipality, Shivapuri Rural Municipality, Dupcheshwor Rural Municipality, Tadi Rural Municipality, Suryagadhi Rural Municipality and Panchakanya Rural Municipality. They were provided a list of questionnaires through Google form for evaluation of the technical parameter of resilience. A total of 29 responses were received after sending the questionnaire. The respondents have worked in various capacities in the reconstruction efforts: construction, social mobilization, documentation, and administrative work. Given the number of respondents and their activities performed, the study team deemed that the received responses were enough to represent the study area and scope.

A set of the questionnaire included 15 questions excluding the respondent's basic information. The questionnaire was structured under six different aspects of the technical parameter of resiliency as explained below.

\section{Site topography and geology}

Site topography and geology is one of the most important aspects to evaluate whether the site is technically safe from hazards or not. The topography of the site area plays a vital role in the safety of structures. In reconstruction work, the responsibility for choosing the appropriate site locations lies with the site engineers/site supervisors. However, in some cases, when the site locality is unfavorable for reconstruction (construction work and future usage by beneficiaries), resettlement is necessary. It is crucial to identify the resettlement area free from the geological faults and hazard inducing topographic features with the help of various resources and equipment. The use of a hazard-zoning map determines whether areas are affected by or susceptible to natural hazards such as earthquakes, landslides, floods, etc. Similarly, the use of land-use planning helps regulate the use of land to have better social and environmental outcomes and efficient use of resources.

\section{Technical supervision}

The building codes/guidelines compliance rate of constructed houses has increased significantly in different areas of the Nuwakot district with an increase in sociotechnical assistance (Dhungel et al., 2019). This shows that technical supervision is one of the most important factors to ensure the safety of structures. Frequent visits to the site help in the timely identification of faults during construction ultimately achieving structural safety. So, it is necessary to know if the buildings have achieved the desired level of technical safety or not as per the judgment of experts working in their areas.

\section{Technically compromised design and construction}

It is important to know whether the Architectural/Engineering design has been compromised to amplify the compliance rate to disburse government subsidy or tranche. If the design has changed, it is vital to know to what extent the design has been modified from the standards/guidelines set by the NRA and Nepal National Building Codes. The requirements of construction material as well as the design parameters for the reconstruction of buildings are determined by space occupancy and function. The factors thus mentioned affect hazard resistance and damage due to the earthquake. The construction costs of buildings are directly related to the design requirements. The beneficiaries may not be economically sound to construct according to the requisite codes and guidelines. This may cause deviation from the design during construction that may result in structural damage of the building due to future earthquakes (Al-Nammari \& Lindell, 2009). Are we not making these buildings more vulnerable to earthquakes due to such modifications? Similarly, due to financial hardships, house owners or masons might have compromised in workmanship and the quality of materials used during construction making the buildings unsafe from a technical point of view.

\section{Training and capacity building}

Training is a critical step in transferring knowledge to stakeholders, not only in participatory processes of design and construction, but also in building capacity to enable community members and local governments to operate and maintain infrastructure systems (Opdyke et al., 2018) The number of masons trained for the construction of buildings with the updated construction guidelines is linked to the number of technically safe houses the masons will build. Similarly, it is essential to measure the retention of earthquake-resistant building construction knowledge in masons and to gather information on whether they are constructing houses as per the guidelines or not. Moreover, sufficient knowledge retention in masons can ensure safe construction in the future as well. Likewise, homeowner awareness is also important to achieve resilient reconstruction. Did we make homeowners sufficiently aware of the impacts of earthquakes and the importance of earthquake-resistant design? It is, therefore, crucial to know about the types of training and capacity building efforts adopted and whether these efforts are sufficient enough to retain the knowledge in masons/beneficiaries or not to achieve technical safety.

\section{Use of information technology}

Information Technology has a broad scope in resilient reconstruction. It helps to document the information such as damaged grades, damaged patterns, construction status, numbers of technical supervision conducted, faulty 
construction, compliance rate of individual houses and community, and knowledge retention of masons and homeowners. Moreover, it helps to retrieve such information making future tracking and supervision, timely intervention before faulty construction, and future learning and researches more efficient and effective. Therefore, it is very important to know whether IT knowledge and skills have been used or not to warrant the technical safety of structures. And if it is used, in which reconstruction phase has it been used predominantly?

\section{Use of buildings vulnerable to earthquakes}

Most of the load-bearing houses in the Nuwakot district have been partially damaged if not completely collapsed and unsafe to use, due to the 2015 Earthquake. These vulnerable buildings may collapse at any time. But instead of retrofitting or demolishing, people have been using these houses as a barn (storing grain, hay, or straw or for housing livestock), kitchen, and some even use them for residential purposes. As a result, the use of vulnerable buildings has become life-threatening because of the lack of adequate earthquake-resistant components making these unsafe from a technical point of view eventually hindering resilient reconstruction. So, it is necessary to identify how these buildings have been used in the postreconstruction phase.

This paper assumes that the experts have put forward their judgments in the structured questionnaires based on the above-mentioned six identified aspects of the technical parameter of the resiliency as per their field experience, expertise, and discernment.

\section{RESULTS}

Of the 29 respondents, 19 were civil engineers, two were civil sub engineers, one was assistant civil sub engineer, four were social mobilizers, two were working in administrative management, and one in information and documentation (Fig. 1).

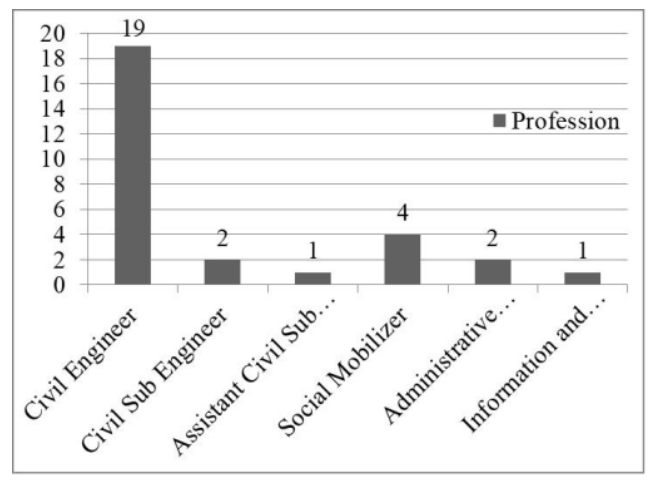

Fig. 1. Numbers of respondents reporting their profession

The majority of respondents (69\%) have worked in hilly terrain with mild slope followed by a steep slope and plain terrain (Fig. 2). Similarly, $51.7 \%$ of respondents said that various resources have been used to identify the safe resettlement areas (Fig. 3). The resettlement areas have been identified through visual inspection, previous experience, and technical judgment. Some responded that hazard-zoning maps for landslide, floods and earthquakes, and soil quality and slope stability checks have been used to identify the vulnerable areas. Moreover, with the help of secondary data available and in coordination with the local government, a detailed analysis of the technical and social aspects of the areas was done.

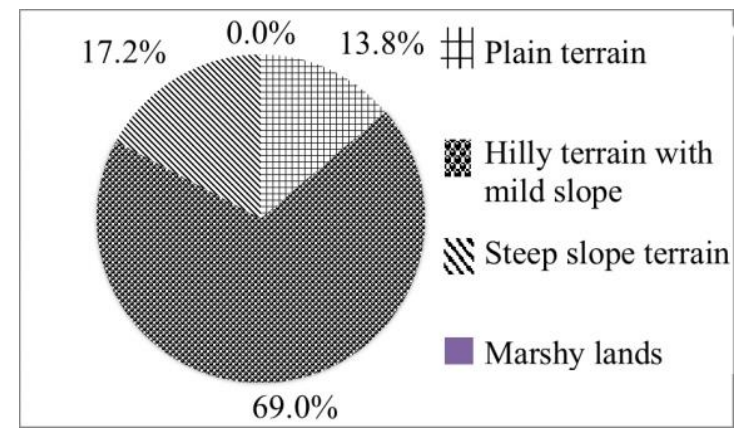

Fig. 2. Percentages of respondents reporting the topography of their working areas

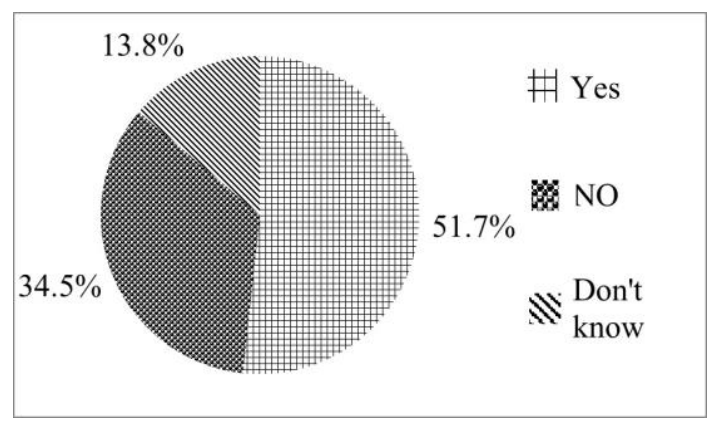

Fig. 3. Percentages of respondents reporting the use of various resources to identify the safe resettlement areas

Majority of the experts $(48.3 \%)$ responded that the average rate of supervision of a building in their working areas was once in a month (Fig. 4). Only $20.7 \%$ said that the supervision was on a day-to-day regular basis (Fig. 4).

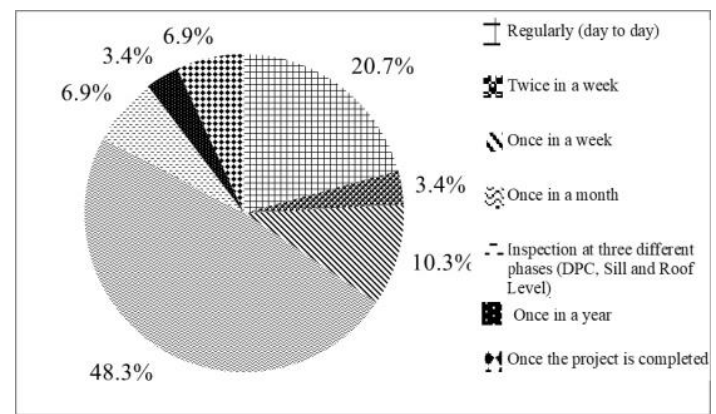

Fig. 4. Percentages of respondents reporting the rate of supervision of buildings in their areas 
Similarly, in a question regarding the impression of constructed buildings from a technical point of view, $62.1 \%$ of the respondents reported that these structures were durable (Fig. 5). Overall, the buildings constructed in their areas were durable and reliable as per the judgment of the participants.

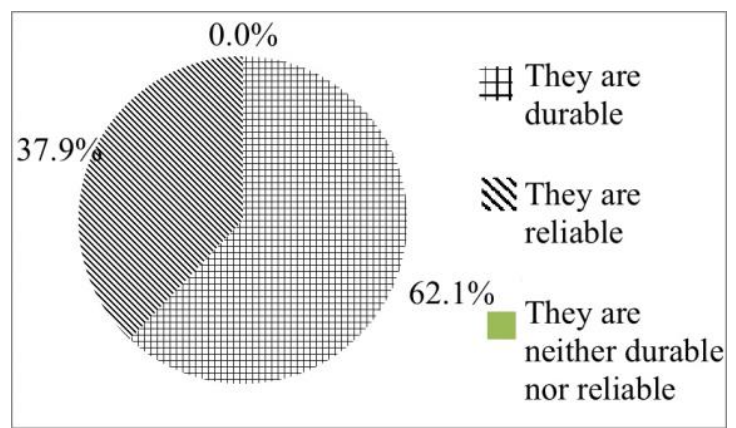

Fig. 5. Percentages of respondents reporting the impression of reconstructed buildings in their areas from a technical point of view

All 29 respondents reported that the government agencies are key bodies to be responsible for the supervision of reconstruction followed by partner organizations (16 respondents) (NGOs/INGOs) working in the related field (Fig. 6).

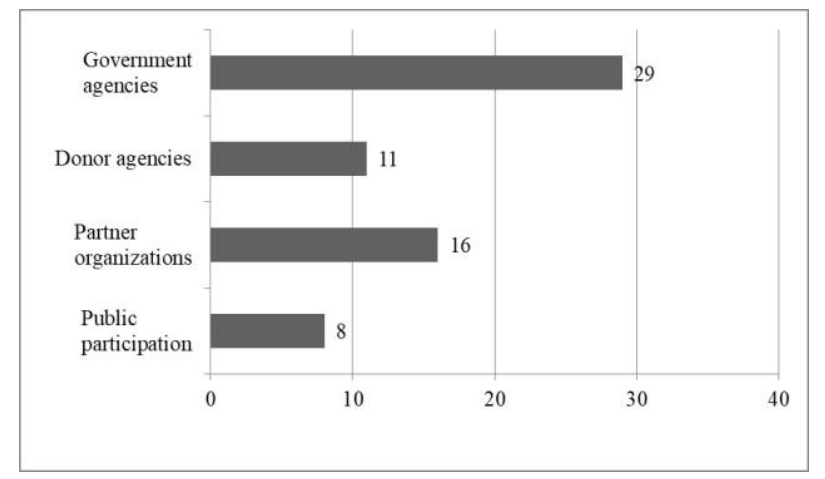

Fig. 6. Numbers (percentages) of respondents reporting the types of organizations responsible for the supervision

As presented in Fig. 7, $51.7 \%$ of the experts responded that the buildings were not vulnerable to earthquakes as there have been no such changes in the design. Similarly, the majority $(62.1 \%)$ of respondents reported that there were some minor alterations in the guideline/specification for the practicability purpose; whereas $3.4 \%$ of experts said that the guideline/specification had been highly compromised making the buildings susceptible to earthquakes (Fig. 8).

Likewise, $41.4 \%$ of the respondents reported that the homeowners/beneficiaries focused equally on quality and cost, and $13.8 \%$ of the experts said that the primary focus of beneficiaries was on the quality of construction (Fig. 9).

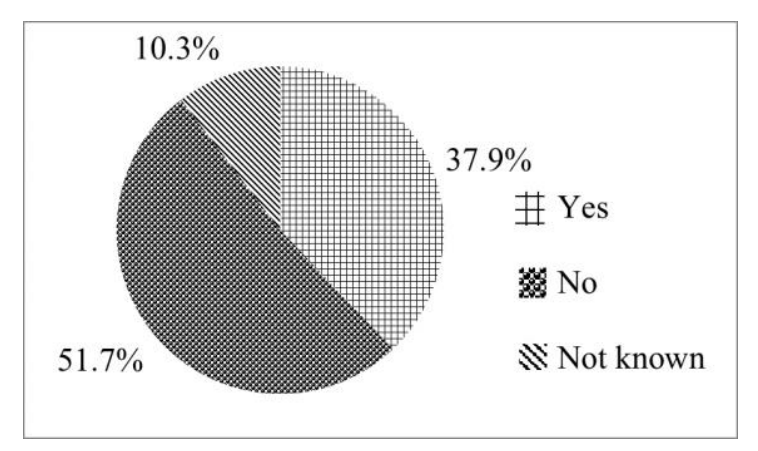

Fig. 7. Percentages of respondents reporting the changes in the design making the buildings vulnerable to earthquakes

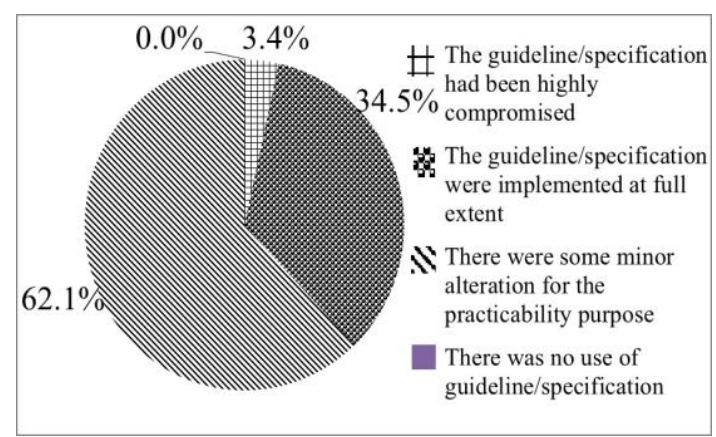

Fig. 8. Percentages of respondents reporting the extent to which the guideline/specification has been compromised

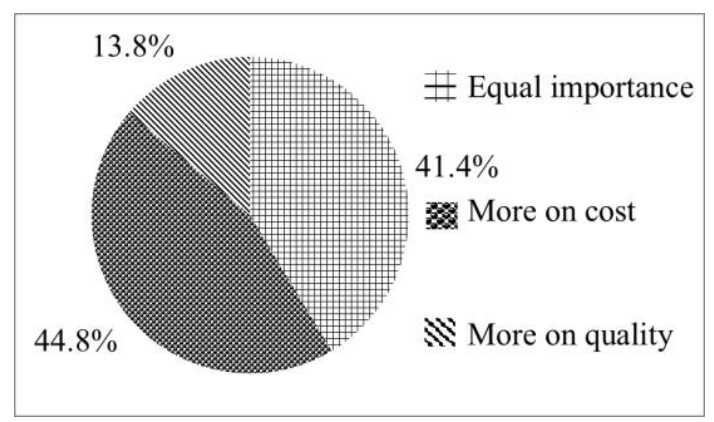

Fig. 9. Percentages of respondents reporting the beneficiaries' primary focus regarding construction

As shown in Fig. 10, 25 experts reported that mason training was conducted in their working areas. A total of 24 experts stated that awareness programs were conducted in their working areas. On the contrary, rescue and recovery training was only conducted in the working areas of five respondents.

Similarly, $82.8 \%$ of the experts responded that there was sufficient knowledge retention in masons (Fig. 11). Likewise, in a question regarding the earthquake safety awareness knowledge, all the respondents reported that the beneficiaries had some information, whereas $48.3 \%$ of the experts said that the knowledge was adequate (Fig. 12). 
Qualitative evaluation of technical parameter of resiliency: a case study of Nuwakot district, Nepal

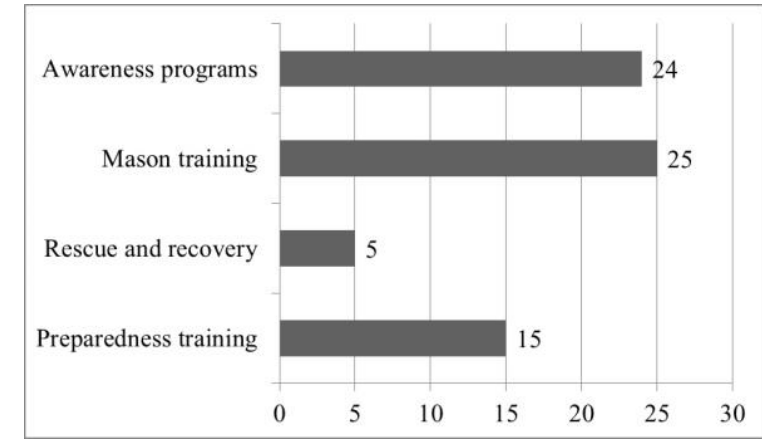

Fig. 10. Numbers of respondents reporting the types of training/capacity building programs implemented in their working areas

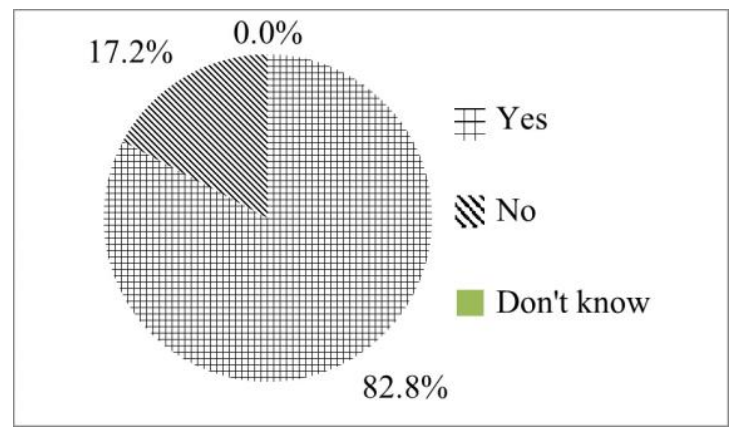

Fig. 11. Percentages of respondents reporting the impression on sufficient knowledge retention in masons

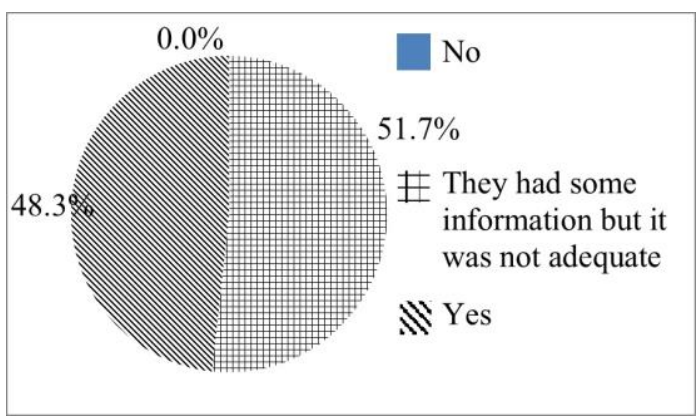

Fig. 12. Percentages of respondents reporting the impression on beneficiaries' earthquake safety awareness knowledge

For a question regarding the uses of the information technology (IT) knowledge/skills, $96.6 \%$ of the respondents reported that their organizations used these skills in the reconstruction process (Fig. 13). Similarly, the majority $(44.8 \%)$ of the experts said that IT was used in the construction phase (Fig. 14), and only $6.9 \%$ reported its use in all phases (designing/planning, construction, and operation/maintenance).

As per Fig. 15, $27.6 \%$ of respondents said that the old vulnerable buildings were used for residential purposes and more than $90 \%$ of experts reported that these buildings were used for various purposes as mentioned in Fig. 15. Only $6.9 \%$ of the respondents said that the vulnerable buildings were not used for any of the purposes

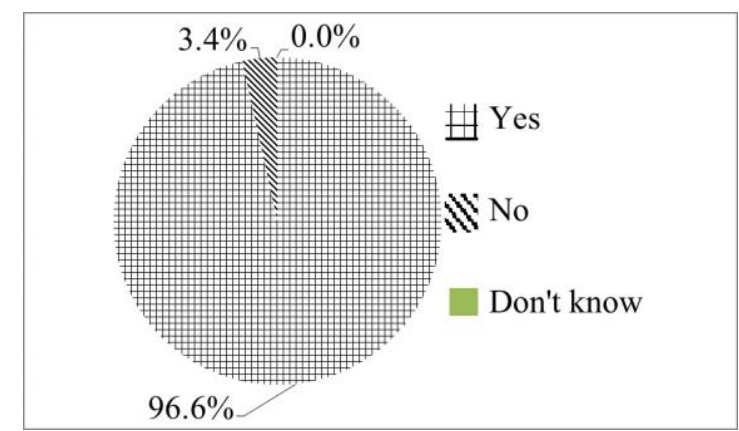

Fig. 13. Percentages of respondents reporting the uses of Information Technology knowledge/skills in the reconstruction

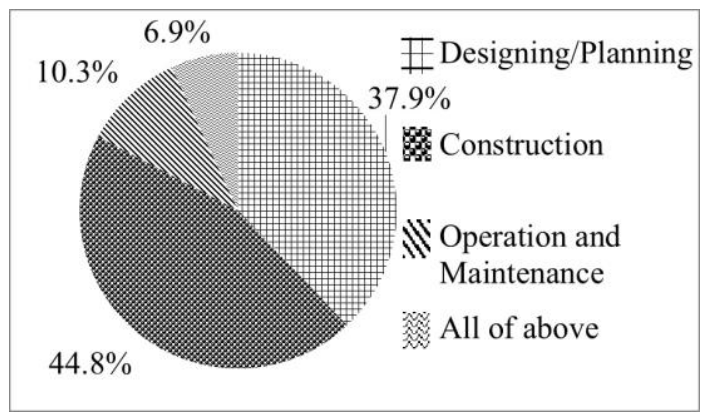

Fig. 14. Percentages of respondents reporting the phases where IT knowledge/skills have been used

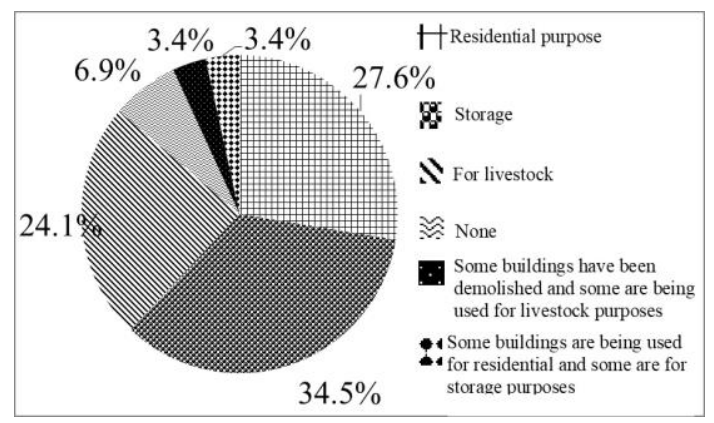

Fig. 15. Percentages of respondents reporting the uses of old vulnerable buildings for various purposes in their areas

\section{DISCUSSION}

The working areas of the majority of respondents (86.2 $\%)$ constitute a hilly terrain with mild to steep slope land, which also represents the topography of the Nuwakot district as a whole (Dangi et al., 2019). Events like earthquakes, landslides, and erosion can easily provoke slope failures in such areas hindering disaster-resilient reconstruction (Civil Seek, 2020). 
The respondents of the questionnaire survey also stated that the use of safe resettlement planning lacked in almost $50 \%$ of the study area. Thus, there is a need to institutionalize the use of hazard-zoning maps and landuse planning in the Nuwakot district to aid in reconstruction efforts and the formation of a resilient community.

Similarly, the respondents also stated that there was a lack of day-to-day supervision in the majority of the areas. Despite intermittent technical visits during reconstruction, the majority of the respondents of the survey reported that the reconstructed structures were durable and reliable from a technical point of view. To achieve the requisite technical safety of the reconstructed structures, all the participants in the survey stated that the most important organizations for technical supervision are Government Agencies. Thus it can be inferred that if government bodies are periodically involved in the supervision of the reconstruction process, it will facilitate the compliance of the reconstructed buildings to the requisite technical guidelines which will ultimately help in the realization of an earthquake resilient community. Furthermore, since the Government line agencies are responsible for the compliance check, approval of reconstructed houses, and disbursing tranches, their proactive involvement in the entire process will streamline the reconstruction efforts.

Although there have been some changes in the standard NRA guidelines of building construction during implementation in the field; the major compromise on technical aspects was significantly low. A total of $45 \%$ of respondents stated that the homeowners focused on the cost. Since the homeowners might compromise on the quality of materials and workmanship to reduce the cost of construction, different alternatives and methods need to be explored to increase awareness about the importance of quality construction.

The respondents reported that the status of mason training, awareness programs, and knowledge retention in masons working in the study area was good. A total of $17 \%$ of the respondents stated that mason refresher training needs to be conducted to help retain the construction knowledge and skills in the remaining masons working in the study area. Based on the response of the survey participants, it seems that there is a need to increase the preparedness, rescue, and recovery training in the Nuwakot district. Likewise, more than $50 \%$ of the respondents stated about the need to disseminate knowledge about earthquake resilience among the house owners, which can be achieved through awareness programs.

From the survey, it was seen that there have been some uses of IT in reconstruction, but the uses were mainly in the designing/planning and construction phase. There is a need to increase the use of IT in the operation and maintenance phase as well. The use of GIS and remote sensing, radio and television, mobile apps, mobile phone and SMS, social networks, alert systems, etc. in the operation and maintenance phase will aid in overall information gathering and communication. This will, in turn, lead to quick identification, understanding, and resolving of technical issues which will contribute to resilience.

Finally, more than $90 \%$ of the experts stated that the buildings vulnerable to earthquakes were being used for various purposes (primarily residential and livestock housing) in the Nuwakot district. Therefore, these buildings must be either demolished or retrofitted for safe usage to achieve a resilient community.

\section{CONCLUSION}

The different aspects evaluated in the study revealed some satisfactory results and some results that needed to be improved to support the formation of an earthquake resilient community. Overall, the majority of the reconstructed houses in the Nuwakot district are compliant and safe from a technical point of view since there are no major compromises in the design of the buildings making them vulnerable to earthquakes. Further, the status of mason training, awareness programs, and knowledge retention in masons was satisfactory. However, there is a need to improve performance in certain areas such as in the use of safe resettlement planning, frequent site supervision, increasing preparedness, rescue, and recovery training, increasing awareness in homeowners, increased use of IT in the operation and maintenance phase, and demolishing or retrofitting vulnerable buildings. The house owners in the study area focused on the cost rather than the quality. Therefore, there is a need to adopt feasible approaches to make them focused on the quality as well in order to achieve an earthquake resilient community

\section{REFERENCES}

Al-Nammari, F.M., \& Lindell, M.K. (2009). Earthquake recovery of historic buildings: exploring cost and time needs. Disasters, 33(3), 457-81

Bruneau, M., Chang, S. E., Eguchi, R. T., Lee, G. C., O'Rourke, T. D., Reinhorn, A. M., Shinozuka, M., Tierney, K., Wallace, W. A., \& Winterfeldt, D. V. (2003). A framework to quantitatively assess and enhance the seismic resilience of communities. Earthquake Spectra, 19, 733-752.

Civil Seek. (2020). CSeek. (Retrieved from https://civilseek.com/slope-failure/)

Dangi, H., Bhattarai, T. N., \& Thapa, P. B. (2019). An approach of preparing earthquake-induced landslide hazard map: a case study of Nuwakot district, central Nepal. Journal of Nepal Geological Society, 58, 153-162. 
Qualitative evaluation of technical parameter of resiliency: a case study of Nuwakot district, Nepal

Dhungel, R., Shrestha, S. N., Guragain, R., Gouli, M. R., Baskota, A., \& Hadkhale, B. (2019). Socio-technical module in assistance: Promoting resilient reconstruction in the wake of a disaster. Journal of Nepal Geological Society, 58, 139-144.

Fallahi, A. (2007). Lessons learned from the housing reconstruction following the Bam earthquake in Iran. Australian Journal of Emergency Management, 22(1), 26-35.

Hall, M. L., Lee, C. K., Cartwright, C., Marahatta, S., Karki, J., \& Simkhada, P. (2017). The 2015 Nepal earthquake disaster: lessons learned on public health.

JRC EC. (2014). Seismic resilience: concept, metrics, and integration with other hazards, In JRC Science and Policy Report. Joint Research Centre, European Commission.

Li, Q., Umaier, K., \& Koide, O. (2019). Research on postWenchuan earthquake recovery and reconstruction implementation: a case study of housing reconstruction of Dujiangyan city. Progress in Disaster Science, 4.

Ministry of Home Affairs, GoN. (2019). Nepal Disaster Report. Kathmandu.

National Planning Commission, GoN. (2015). Post Disaster Needs Assessment. Kathmandu.
NRA. (2016). Post Disaster Recovery Framework. National Reconstruction Authority, Government of Nepal, Kathmandu.

NRA. (2020). National Reconstruction Authority. National Reconstruction Authority, Government of Nepal. (Retrieved from http://www.nra.gov.np/en/mapdistrict/datavisualizati on)

NDRRP. (2020). Nepal Disaster Risk Reduction Portal. Nepal Disaster Risk Reduction Portal, Government of Nepal, Kathamndu (Retrieved from http://drrportal.gov.np/risk-profile-of-nepal).

Opdyke, A., Javernick-Will, A., \& Koschmann, M. (2018). A comparative analysis of coordination, participation, and training in post-disaster shelter projects. Sustainability, 10, 4241.

Sharma, K., KC, A., Subedi, M., \& Pokharel, B. (2018). Post-disaster reconstruction after 2015 Gorkha earthquake: challenges and influencing factors. Journal of the Institute of Engineering, 14(1), 52-63.

Yaoxian, Y. (1996). Decision-making for recovery and reconstruction following a strong earthquake. In Post-Earthquake Rehabilitation and Reconstruction (pp. 59-68). $\quad$ https://doi.org/10.1016/B978008042825-3/50009-0 